\title{
The Predictive Value of the Pentraxin 3 Concentration in Cumulus Cell Culture Media for the Embryo Implantation
}

\author{
Tulay IREZ1, Yavuz SAHIN², Eduard MALIK³, Onur GURALP³ \\ Istanbul, Türkiye
}

\section{ABSTRACT}

OBJECTIVE: Many studies on the interrelation of cumulus cells and oocytes, and research on cumulus protein factors continue. This study aims to investigate the relationship of Pentraxin 3 level with embryo implantation in the cumulus culture fluid.

STUDY DESIGN: A total of 31 women with idiopathic infertility who underwent intracytoplasmic sperm injection treatment were prospectively evaluated. Cell suspensions containing $5 \mathrm{million} / \mathrm{mL}$ cumulus cells were obtained post-hyase and incubated for 24 hours in a culture medium. A possible association between the culture media Pentraxin 3 concentrations and embryo implantation was analyzed.

RESULTS: The cumulus cell culture media Pentraxin 3 concentrations were significantly higher in the pregnant group compared to the non-pregnant group $(98.9 \mathrm{ng} / \mathrm{mL}$ vs $53.2 \mathrm{ng} / \mathrm{mL}$, respectively, $p=0.005)$. There was a significant positive correlation between the culture media Pentraxin 3 concentrations and embryo implantation $(r=0.500, p=0.005)$. The culture media Pentraxin 3 concentration was a significant predictor for successful embryo implantation (AUC=0.845, $p=0.006$ ). A cut-off value of $64.25 \mathrm{ng} / \mathrm{mL}$ had an $86 \%$ sensitivity and $80 \%$ specificity to predict embryo implantation. There was no pregnancy under the cut-off value of $60 \mathrm{ng} / \mathrm{mL}$, whereby seven women had good quality grade 1 oocytes according to the traditional morphological criteria.

CONCLUSION: The cumulus cell culture medium Pentraxin 3 concentration was predictive for successful embryo implantation. Low Pentraxin 3 levels $(<60 \mathrm{ng} / \mathrm{mL}$ were associated with failure of conception.

Keywords: Cumulus granulosa cell, In vitro fertilization, Pentraxin 3

Gynecol Obstet Reprod Med 2022;28(2):157-163

\section{Introduction}

One of the most important parameters in assisted reproductive technologies is the selection of the embryo with high implantation capacity. The traditional selection criteria in-

\footnotetext{
${ }^{1}$ Faculty of Medicine Department of Histology \& Embryology Istanbul Yeni Yuzyll University, Istanbul, Türkiye

${ }^{2}$ Ministry of health, Ankara, Türkiye

3 Department of Gynecology and Obstetrics University of Oldenburg, Germany

Address of Correspondence: Prof. Dr. Tulay Irez

Istanbul Yeni Yuzyil University, Faculty of

Medicine Department of Histology and

Embryology Head of Clinical Embryology

Master program. Yllanll Ayazma cad.no:26

34010, Maltepe-Topkapi, Istanbul, Türkiye

ireztulay@yahoo.com
}

Submitted for Publication: 14.02.2021 Revised for Publication: 15.02.2021 Accepted for Publication: 13.07.2021 Online Published: 02.09.2021

ORCID IDs of the authors: TI: 0000-0001-8272-4931

YS: 0000-0001-6784-0766, EM: 0000-0002-0731-6150 OG: 0000-0002-3517-3046

\begin{tabular}{c|c}
\hline Quick Response Code: & Access this article online \\
\cline { 2 - 2 } & Website: www.gorm.com.tr \\
& e- mail: info@gorm.com.tr \\
\hline
\end{tabular}

How to cite this article: Irez T. Sahin Y. Malik E. Guralp O. The Predictive Value of the Pentraxin 3 Concentration in Cumulus Cell Culture Media for the Embryo Implantation. Gynecol Obstet Reprod Med. 2022;28(2):157-163

clude morphological criteria, early cleavage, fragmentation rate, and blastocyst structure (1). With the help of advances in technology, new biological markers have been discovered for the selection of the oocyte and embryo (2).

Objective markers with high predictive value are essential for the selection. Moreover, it is important to maintain the viability of the oocyte during the molecular analysis for the selection. For that reason, the follicle fluid and cumulus ooforus complex are very suitable for molecular analyses (3).

Pentraxin 3 (PTX3) is an extracellular matrix protein expressed by somatic and immune cells. PTX3 is also an inflammatory molecule and synthesized in the liver and various blood cells. PTX3 was suggested as a marker for preeclampsia (4). Rovere-Querini et al. (5) have shown that the plasma levels of PTX3 in placenta tissue were significantly higher in preeclamptic compared to non-preeclamptic women. Lekva et al. (6) have shown that serum PTX3 is low in gestational diabetes.

In cumulus cells, PTX3 is secreted in case of inflammatory stimulus (7). Recent studies showed that PTX3 is directly associated with the stability of the extracellular matrix supporting the cumulus cells (8). 
Pentraxin 3 protein has been shown to play an important role in the optimal expansion of the cumulus cells and supporting hyaluronic acid (9). It also plays an important role in in vivo fertilization (10). Animal studies have shown that it is instrumental in the maturation of the oocyte and transtubal transport (11).

Considering the previous data, we aimed to evaluate the possible association between PTX3 concentration in cumulus cell culture medium and oocyte maturation and embryo quality as well as fertilization and implantation rates.

\section{Material and Method}

This study was conducted between November 2014 and March 2015 in Zeynep Kamil Hospital's in vitro fertilization (IVF) unit in Istanbul. Primary human cumulus cells were obtained with informed patient consent after approval from the Zeynep Kamil Women Hospital Ethics Board at October 2014/728 number. All procedures performed were in accordance with the ethical standards of the institutional and/or national research committee and with the 1964 Helsinki declaration and its later amendments or comparable ethical standard. The study was performed in accordance with approved guidelines. Informed consent was obtained from all individual participants included in the study. A total of 31 couples with unexplained infertility, who were treated in our clinic, were included. Inclusion criteria were female, age $<35$, and normal sperm count test parameters. The couples with female factors, women $<18$ and $>36$ years were excluded from the study.

The controlled ovarian stimulation protocol for in vitro fertilization (IVF) patients consisted of follicular phase GnRH antagonist (Ganirelix; Merck, Turkey) down-regulation. Gonadotropin stimulation began on menstrual cycle day 2 with human menopausal gonadotropin (hMG; Menopur, Ferring, Turkey) and recombinant FSH (Puregon, Merck, Turkey). Following ovulation induction, the antral follicles were counted. Oocyte pick-up (OPU) was performed 36 hours after the human chorionic gonadotropin (HCG) $\left(\right.$ Pregnyl $\left.{ }^{\circledR}\right)$ injection. The OPU procedure was performed under ultrasound guidance. The oocytes were incubated for 2-4 hours in a human tubal fluid (HTF) fertilization medium (Life Global) followed by a denudation procedure with hyaluronidase (Life Global). After the ICSI procedure, the oocytes were kept in an HTF fertilization medium (Life Global).

In our study, the oocytes with clear, light, and nongranulated cytoplasm, normal thickness of zona pellucida, and normal-sized polar body were scored as oocyte score 1; whereas oocytes with two or more of the unfavorable criteria such as a dark or granulated cytoplasm, thick zona pellucida, and large or small polar body were classified as score 2 oocytes.

The fertilization check was performed 16-18 hours after the ICSI procedure, and the embryos were cultured in the cleavage medium (Life Global). The evaluation of the embryos was performed according to the European Society of Human Reproduction and Embryology (ESHRE), the American Society of Reproductive Medicine (ASRM), and the Alpha 2011 Consensus (12). According to the cumulative evaluation of the embryos, women who have $>70 \%, 70-20 \%$, and $<20 \%$ of good quality embryos were scored with 1 (best), 2 , and 3 (worst), respectively.

Once the granulosa cells were removed from the oocytes, the remaining cumulus cells were washed twice with the G-1 PLUS medium (Vitro Life). The cumulus cells were counted in a Neubauer chamber and were distributed to the containers, with 5 million cells $/ \mathrm{mL}$ in each container. Every container was filled up to $1 \mathrm{~mL}$ with G-IVF PLUS medium (Vitro Life) and was incubated for 24 hours. The cell culture suspensions were centrifuged at $5000 \mathrm{rpm}$ for 10 minutes, and the supernatants were labeled. All samples were frozen at $-80^{\circ} \mathrm{C}$ until the analysis. A total of 260 oocytes were obtained from 31 patients in our study. 201 of these oocytes were in the metaphase 2 stage. Oocyte denudation was performed separately in oocytes obtained from each selected patient, and the resulting cumulus cells were washed twice in HTF medium (1500 rpm/10 min) and the cell concentration was adjusted to 5 million cells $/ \mathrm{ml}$ and HTF medium and 10\% albumin were added and cultured for 24 hours. Supernatants were collected, numbered for each oocyte, and frozen at $-80^{\circ} \mathrm{C}$ until it was assayed. PTX3 determinations were made by the ELISA method only in the transferred embryo culture supernatant. Embryo transfer was done on the 3rd day with 1 or 2 embryos. In 2 embryo transfer cases, each embryo's PTX3 value was given as the mean value. Enzyme-linked immunosorbent assay, human PTX3 by sandwich assay (Abcam, UK, ab 214570). The sensitivity of the test was $3.4 \mathrm{pg} / \mathrm{ml}$, and the range was $15.6 \mathrm{pg} / \mathrm{ml}-1000$. Kit includes human PTX3 capture antibody, HPTX3 lyophilized recombinant protein for control, cell extraction buffer, tetramethylbenzidine substrate, stop solution and anti-tag coated microplates (96 wells). This kit can use for human tissue culture supernatants, serum, or plasma. Embryo transfer was performed in 1 or 2 embryo transfers. In 2 embryo transfer cases, each embryo's PTX3 value was given as the mean value.

The semen analysis was performed according to the World Health Organization (WHO) 2010 criteria and the good quality sperm were isolated by the density gradient method (13). The oocytes were yielded from the follicles with a diameter of $>18 \mathrm{~mm}$. The fertilization was achieved by ICSI and the embryo was followed up.

\section{Preparation of the patients}

All patients were stimulated with the antagonist protocol. Controlled ovarian stimulation (COS) was initiated on cycle day 2 or 3 and continued until the day of ovulation induction. A fixed dose of rFSH was used for the first 6 days, $150 \mathrm{IU}$ according to $\leq 36$ years of age. After 6 days of stimulation, the 
rFSH doses were adjusted according to ovarian response evaluated using transvaginal ultrasonography. A daily $\mathrm{GnRH}$ antagonist (Ganirelix-Orgalutran ${ }^{\circledR}$; MSD, Ballerup, Denmark) dose of $0.25 \mathrm{mg}$ was used starting on stimulation day 6 and was administered until the day of ovulation induction $(14,15)$. The follicle growth was followed up by regular ultrasonographic examinations. By adequate growth of the follicles $(>18 \mathrm{~mm})$, recombinant chorionic gonadotropin was used to induce ovulation. The oocytes were picked up 36 hours after the HCG injection. Pregnancy was defined by the demonstration of the heartbeat-positive embryo with ultrasound.

\section{Statistical analysis}

Homogeneous parametric variables were expressed as mean \pm standard deviation, minimum, and maximum; non-homogeneous parametric variables were expressed as median, minimum, and maximum. Homogenous parametric variables were evaluated with a t-test and ANOVA. Non-homogenous variables were evaluated with the Mann-Whitney-U-Test. Non-parametric variables were evaluated with a chi-square test. Statistical analyses were performed using SPSS 22 (Statistical Package for Social Science) for Windows 10.0. A $\mathrm{p}<0.05$ value was accepted as significant.

\section{Results}

The comparison of the demographic and clinical features of the pregnant $(n=7)$ and non-pregnant $(n=24)$ groups is presented in table I. The cumulus cell culture media PTX3 concentrations were significantly higher in the pregnant group compared to the non-pregnant group (98.9 ng/mL vs 53.2 $\mathrm{ng} / \mathrm{mL}$, respectively, $\mathrm{p}=0.005$, Mann Whitney-U). There was no significant difference in patient ages, BMI, Gonadotrophin doses, days of follicle induction, the total number of oocytes, the number of MI and GV oocytes between the two groups.

The rate of oocyte score 2 was significantly higher in pregnant compared to non-pregnant women $(\mathrm{n}=17$ vs $\mathrm{n}=4$, $p=0.049$ ).

The multivariate regression analysis showed that PTX3 was associated with pregnancy $(ß$ quotient $=0.385, p=0.009$ ) (Table II).

The PTX3 concentration had a significant predictive value for pregnancy, as shown by the ROC analysis (AUC $=0845$, $p=0.006$ ) (Figure 1). A level of $64.25 \mathrm{ng} / \mathrm{mL}$ had a sensitivity of $86 \%$ and a specificity of $80 \%$, respectively (Table III).

Table I: The comparison of the demographic and clinical features of the pregnant and non-pregnant groups

\begin{tabular}{|c|c|c|c|}
\hline & $\begin{array}{c}\text { Non-pregnant } \\
\quad(n=24) \\
\text { mean } \pm S D\end{array}$ & $\begin{array}{l}\text { Pregnant } \\
\quad(n=7) \\
\text { mean } \pm S D\end{array}$ & $p$ \\
\hline Age (year) & $30.00 \pm 3.83$ & $32.00 \pm 3.51$ & 0.182 \\
\hline BMI $\left(\mathrm{kg} / \mathrm{m}^{2}\right)$ & $25.98 \pm 3.79$ & $25.60 \pm 4.63$ & 0.488 \\
\hline Antral follicle $(n)$ & $12.83 \pm 4.36$ & $12.00 \pm 4.04$ & 0.532 \\
\hline Gonadotropin dose (IU) & $2158 \pm 945$ & $2135 \pm 1113$ & 0.800 \\
\hline Duration of follicle induction (days) & $9.2 \pm 2.0$ & $8.5 \pm 1.9$ & 0.532 \\
\hline Endometrial thickness (mm) & $10.97 \pm 2.42$ & $9.90 \pm 0.99$ & 0.274 \\
\hline Total number of oocytes $(n)$ & $8.25 \pm 4.56$ & $8.29 \pm 3.03$ & 0.661 \\
\hline MII oocyte (n) & $6.13 \pm 4.26$ & $6.57 \pm 2.44$ & 0.627 \\
\hline Number of MII oocytes/total number of oocytes & $0.71 \pm 0.26$ & $0.79 \pm 0.14$ & 0.438 \\
\hline M1 (n) & $1.50 \pm 0.97$ & $1.40 \pm 0.54$ & 0.859 \\
\hline GV $(n)$ & $3.25 \pm 2.05$ & $2.00 \pm 1.41$ & 0.533 \\
\hline Pentraxin 3 (ng/ML & $53.22 \pm 21.92$ & $98.98 \pm 70.45$ & 0.005 \\
\hline
\end{tabular}

Table II: The multivariate regression analysis

\begin{tabular}{lcccc}
\hline Model & \multicolumn{2}{c}{ Non-standardized quotient } & Standardised quotient & $t$ \\
& $\beta$ & Standard error & $\beta$ & $p$ \\
\hline Constant & -0.358 & 0.129 & \multirow{2}{*}{0.385} & -2.782 \\
Pentraxin concentration & 0.004 & 0.001 & 0.010 \\
\hline
\end{tabular}

Table III: Sensitivity and specificity values according to various cut off levels

\begin{tabular}{lcc}
\hline Pentraxin level & Sensitivity & Specificity \\
\hline $60.00 \mathrm{ng} / \mathrm{mL}$ & $100 \%$ & $67 \%$ \\
$64.25 \mathrm{ng} / \mathrm{mL}$ & $86 \%$ & $80 \%$ \\
$95 \mathrm{ng} / \mathrm{mL}$ & $14 \%$ & $96 \%$ \\
\hline
\end{tabular}




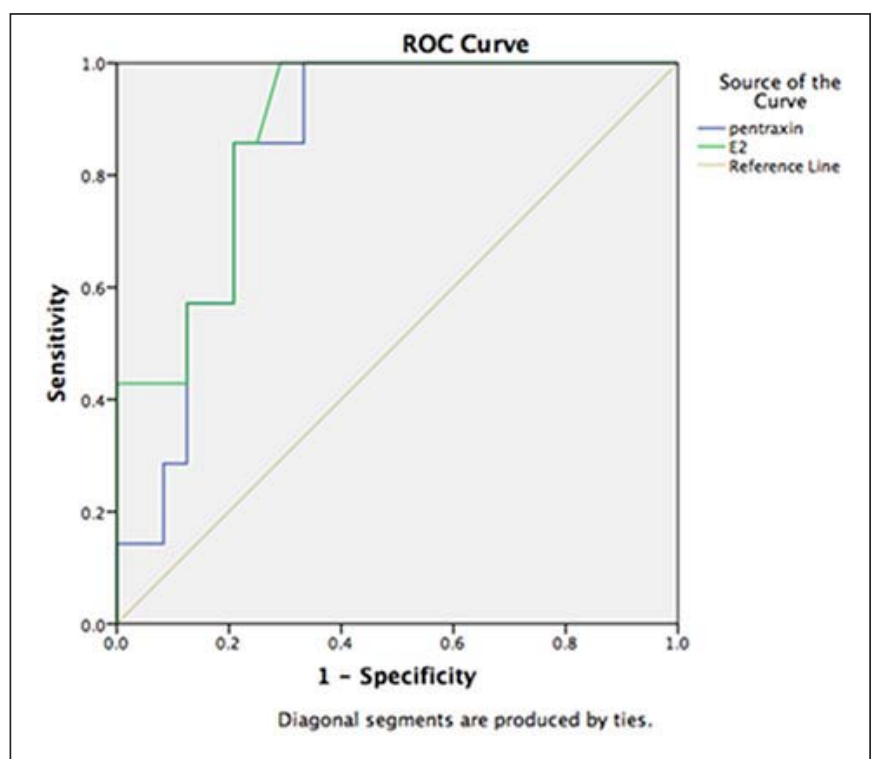

Figure 1: The ROC Analysis for the predictive role of the PTX3 concentration for pregnancy

There was no pregnancy under the cut-off value of 60 $\mathrm{ng} / \mathrm{ml}$, whereby seven women had score 2 oocytes according to the traditional morphological criteria (Table IV).

The PTX3 concentration was significantly higher in the grade 1 embryo group compared to the grade 2 and grade 3 embryo groups (Table V).
Table VI shows pregnancies due to the embryo transfer day. There was no statistical difference between the groups.

\section{Discussion}

The extracellular matrix surrounding the cumulus cells contains hyaluronic acid. Recent studies have shown that hyaluronic acid is associated with the stability of the cumulus cells, and PTX3 protein regulates matrix synthesis $(16,17)$. During ovulation, the synthesis of the cumulus matrix increases initially and decreases with the increased protease secretion of the follicular wall $(18,19,20)$. Salustri et al. (1996) have shown that the PTX3 had a role in the cumulus expansion and matrix organization as well as normal IVF procedure (16). Varani et al. detected the presence of subfertility in PTX3 knockout mice (7). The studies on knockout mice have shown that the reduction of the PTX3 is associated with failure of cumulus oophorus expansion and in vitro fertilization (21). In 2013, Huang et al. (22) evaluated the association between the cumulus gene expression of 7 different genes, including glutathione peroxidase 3 and PTX3, and the fertilization and embryo development in women with polycystic ovaries. The authors have shown that decreased PTX3 expression was associated with a high multinucleation rate and an abnormal fertilization rate (22). The microarray findings obtained from the cumulus culture cells of the women with PCOS showed that PTX3 is associated with fertilization (22).

Table IV: The oocyte scores and PTX3 levels in the pregnant and nonpregnant groups

\begin{tabular}{lccc}
\hline & Nonpregnant & Pregnant & Total \\
\hline PTX $<60 \mathrm{ng} / \mathrm{mL}$, OS 2 & 8 & 0 & 8 \\
PTX $<60 \mathrm{ng} / \mathrm{mL}$, OS 1 & 7 & 0 & 7 \\
PTX $>60 \mathrm{ng} / \mathrm{mL}$, OS 2 & 4 & 1 & 5 \\
PTX $>60 \mathrm{ng} / \mathrm{mL}$, OS 1 & 5 & 6 & 11 \\
PTX3, pentraxin 3; OS, oocyte score. OS 2 indicates bad quality oocytes, whereas OS 1 indicates good quality oocytes.
\end{tabular}

Table V: Comparison of the PTX3 levels according to the embryo grading

\begin{tabular}{lrcrr}
\hline & $\mathrm{n}$ & $\begin{array}{c}\text { Mean } \pm \text { Standard } \\
\text { Deviation }(\mathrm{ng} / \mathrm{mL})\end{array}$ & $\begin{array}{c}\text { Minimum } \\
(\mathrm{ng} / \mathrm{mL})\end{array}$ & $\begin{array}{c}\text { Maximum } \\
(\mathrm{ng} / \mathrm{mL})\end{array}$ \\
\hline Grade 1 embryo (the best quality) & 20 & $77.9 \pm 44.4$ & 48.8 & 257.6 \\
Grade 2 embryo & 7 & $39.3 \pm 16.5$ & 13.6 & 55.0 \\
Grade 3 embryo (the worst quality) & 4 & $33.9 \pm 19.9$ & 4.7 & 47.8 \\
Total & 31 & $63.5 \pm 41.7$ & 4.7 & 257.6 \\
\hline
\end{tabular}

Table VI: Pregnancies due to the embryo transfer day

\begin{tabular}{lcccc}
\hline $\mathrm{n}$ & Non pregnant & pregnant & Total & $p$ \\
\hline 2. day & 3 & 1 & 4 & 22 \\
3. day & 16 & 6 & 5 & 0.417 \\
5. day & 5 & 0 & 31 \\
Total & 24 & 7 & 31 \\
\hline
\end{tabular}


However, Li et al. (23) could not detect any association between the cumulus PTX3 expression and embryo quality.

Zhang et al. evaluated gene expressions in cumulus cells by microarray analysis and suggested that PTX3 could be used as a potential marker to predict oocyte quality (24). In our study, PTX3 was found to be related to oocyte and embryo quality.

Gebhart et al. (21) evaluated the potential associations between the expression of various genes in human cumulus cells and clinical pregnancy and live birth rates. Considering the gene expressions, they tried to detect the genes related to oocyte development. They assessed the genes such as aldolase, fructose-bisphosphate A, lactate dehydrogenase A, phosphofructokinase protein, and pyruvate kinase muscle 2 , which play roles in the metabolical process; genes such as apoptotic cell-induced activity, gremlin 1, prostaglandin-endoperoxide synthase 2 , and steroid sulfatase, which play roles in signaling pathways; and hyaluronic acid synthetase 2, PTX3, TNTNF alpha induced protein 6, and versican, which are related to the extracellular matrix. They found that PTX3 mRNA expression was significantly higher in the pregnant group (21). This finding is in accordance with our study.

In our study, we detected that the pentraxin secretion in cumulus cell culture was significantly higher in the embryo groups with successful implantation. This finding is in accordance with the gene expression studies (21-23). The use of PTX3 in addition to inadequate morphological criteria may be beneficial to select the oocytes with a higher fertilization capacity in assisted fertilization technologies.

Experimental studies show that PTX3 expression may be affected by gonadotropin stimulation (25-27). However, Paffoni et al. (28) have found that human follicular fluid PTX3 levels did not change with ovarian stimulation and were not related to the oocyte quality. Due to the inconsistent results in previous studies, we preferred to recruit women who underwent the same stimulation protocol.

In our study, the multivariate regression analysis showed that PTX3 was associated with pregnancy. The ROC curve showed that a cut-off value of $64.25 \mathrm{ng} / \mathrm{ml}$ had a sensitivity of $86 \%$ and specificity of $80 \%$ to predict the pregnancy. Moreover, a cut-off value of $60 \mathrm{ng} / \mathrm{ml}$ had a $100 \%$ sensitivity for the prediction of pregnancy. However, publications are scarce about PTX3 and pregnancy rates in the literature.

Another interpretation of our results is that the PTX3 levels lower than $60 \mathrm{ng} / \mathrm{ml}$ may be an indicator that achievement of pregnancy is difficult. In other words, rather than saying high levels of PTX3 may predict pregnancy, it is more accurate to say low PTX3 levels may predict failure of pregnancy. Namely, there was no pregnancy in our study with a PTX3 level under $60 \mathrm{ng} / \mathrm{ml}$ in 15 women. However, according to the morphological criteria, seven of these 15 women had an oocyte score of 1 but did not conceive. In these seven women, the morphological score showed a good prognosis, although PTX3 levels indicated a bad prognosis. This finding shows the inadequacy of the morphological criteria.

The selection of embryos with a good morphology is known to be associated with higher pregnancy rates (29), as is also shown in our study. We also detected that pentraxin secretion was increased in cumulus cells of the good-quality embryos. Seli et al. (30) performed a study on the predictive value of fifth-day embryo morphology on pregnancy and compared metabolomic viability with morphological scoring. They have shown that a combination of metabolomic viability and morphological scoring had a higher predictive value for pregnancy than morphological scoring alone (30). Table IV also shows the oocyte score and pregnancy relationship according to pentraxin level. When the oocyte score is above 60 $\mathrm{pg} / \mathrm{ml}$, pregnancy occurs. Again, pregnancy can not be seen in cases with an oocyte score of 1 in the same table and below 60 $\mathrm{pg} / \mathrm{ml}$ of PTX3 In this case, the PTX3 level in the culture supernatant was found to be superior to the oocyte morphology score in determining pregnancy. In addition, Table $\mathrm{V}$ shows that the embryo score and PTX3 value are closely related. The mean ptx value of grade 1 embryos transferred in 20 cases was $77.9 \mathrm{pg} / \mathrm{ml}$. Grade 2 and grade 3 embryo transfer rates were 39.3 and $33.9 \mathrm{pg} / \mathrm{ml}$, respectively. These results indicate that morphological assessment is still valuable in IVF applications.

The ovulation process is governed by many endocrine and paracrine factors. Examination of various factors necessary for egg production in the investigation of unexplained female infertility will provide a better understanding of this issue. Studies have shown that PTX3 has an important role in the GDF signal transduction cascade in the cumulus-oocyte interaction during the periovulatory period (31). It has been found that PTX3 is synthesized in the periovulatory follicle before ovulation by cumulus oophorus and plays a role in the organization of a hyaluronan-rich matrix required for successful fertilization (32). With mouse studies, it has been shown that when PTX3 is not synthesized, there is a normal amount of hyaluronan synthesis, but matrix stabilization does not occur. Studies with mice cumulus culture have shown that exogenous PTX3 administration restores matrix organization (9). We think that this study will make an important contribution to unexplained female infertility and will bring an important perspective in the selection of embryos with implantation ability in embryo development.

Our study group consisted of pairs with unexplained infertility. Sperm and oocyte factors were eliminated by conventional methods. However, it is well known that the implantation process is multifactorial. Endometrial receptivity, as well as sperm DNA integrity, plays an essential role in implantation. In addition to the WHO criteria, sperm DNA and matu- 
ration analysis may be used to evaluate sperm quality to exclude the malefactor in such studies. This may be addressed as a weakness of our study. Larger scaled studies are needed to define the sensitivity and specificity rates.

\section{Conclusion}

Cumulus cell PTX3 concentration has predictive value on embryo grade and pregnancy. Low PTX3 levels $(<60 \mathrm{ng} / \mathrm{ml})$ were associated with failure of conception, which has not been accurately predicted according to the traditional morphological oocyte scoring.

Acknowledgments: This research did not receive any specific grant from any funding agency in the public, commercial or not-for-profit sector

Competing interests: We have no conflict of interest to report. Funding: None

Consent for publication: We understand that the text and any pictures published in the article will be freely available on the internet and may be seen by the general public. The pictures and text may also appear on other websites or in print, may be translated into other languages, or used for commercial purposes. We have been offered the opportunity to read the manuscript

Ethics: Ethics approval and consent to participate; Primary human cumulus cells were obtained with informed patient consent after approval from the Zeynep Kamil Women Hospital Ethics Board by the number, Oct 2014/214 KD.

Availability of data and material: Study data are recorded in the spss program, can be given at any time

Authors' contributions: Design of study; T.I., E.M., O.G., Experimentation: Y.S., Statistics: O.G.

\section{References}

1. Ebner T, Moser M, Sommergruber M, Tews G. Selection based on morphological assessment of oocytes and embryos at different stages of preimplantation development: a review. Hum Reprod Update. 2003;9(3):251-62. Doi: 10.1093/humupd/dmg021.

2. Hillier SG. Research challenge: what is the best non-invasive test of oocyte/embryo competence? Mol Hum Reprod. 2008;14(12):665. Doi: 10.1093/molehr/gan068.

3. Matos L, Stevenson D, Gomes F, Silva-Carvalho JL, Almeida H. Superoxide dismutase expression in human cumulus oophorus cells. Mol Hum Reprod. 2009;15(7): 411-9. Doi: 10.1093/molehr/gap034.

4. Larsson A, Palm M, Helmersson J, Axelsson O. Pentraxin 3 values during normal pregnancy. Inflammation. 2011; 34(5):448-51. Doi: 10.1007/s10753-010-9252-x.

5. Rovere-Querini P, Antonacci S, Dell'Antonio G, Angeli A, Almirante G, Cin ED, et al. Plasma and tissue expression of the long pentraxin 3 during normal pregnancy and preeclampsia. Obstet Gynecol. 2006;108(1):148-55. Doi:
10.1097/01.AOG.0000224607.46622.bc.

6. Lekva T, Lyle R, Roland MC, Friis C, Bianchi DW, Jaffe $\mathrm{IZ}$, et al. Gene expression in term placentas is regulated more by spinal or epidural anesthesia than by late-onset preeclampsia or gestational diabetes mellitus. Sci Rep. 2016;6:29715. Doi: 10.1038/srep29715.

7. Varani S, Elvin JA, Yan C, DeMayo J, DeMayo FJ, Horton HF, et al. Knockout of pentraxin 3, a downstream target of growth differentiation factor-9, causes female subfertility. Mol Endocrinol. 2002;16(6):1154-67. Doi: 10.1210/mend.16.6.0859.

8. Chang HM, Fang L, Cheng JC, Klausen C, Sun YP, Leung PC. Growth differentiation factor 8 down-regulates pentraxin 3 in human granulosa cells. Mol Cell Endocrinol. 2015;404:82-90. Doi: 10.1016/j.mce.2015.01.036.

9. Salustri A, Garlanda C, Hirsch E, De Acetis M, Maccagno A, Bottazzi B, et al. PTX3 plays a key role in the organization of the cumulus oophorus extracellular matrix and in in vivo fertilization. Development. 2004;131(7):1577-86. Doi: $10.1242 / \mathrm{dev} .01056$

10. Suarez SS. Gamete and zygote transport. In: Plant TM, Zeleznich AJ, editors. Knobil and Neill's Physiology of Reproduction. 4th. Vol. 1. Elsevier; Oxford: 2015. pp. 197-232.

11. Di Giacomo M, Camaioni A, Klinger FG, Bonfiglio R, Salustri A. Cyclic AMP-elevating agents promote cumulus cell survival and hyaluronan matrix stability, thereby prolonging the time of mouse oocyte fertilizability. J Biol Chem. 2016;291:3821-36. Doi: 10.1074/jbc.M115.680 983

12. Alpha Scientists in Reproductive Medicine and ESHRE Special Interest Group of Embryology. The Istanbul consensus workshop on embryo assessment: proceedings of an expert meeting. Hum Reprod. 2011;26(6):1270-83. Doi: 10.1093/humrep/der037.

13. World Health Organisation. WHO lab manual for the examination and processing human semen ( $5^{\text {th }}$ edition), 2010. ISBN 9789241547789, WHO press: Geneva, Switzerland.

14. D'Amato G, Caroppo E, Pasquadibisceglie A, Carone D, Vitti A, Vizziello GM. A novel protocol of ovulation induction with delayed gonadotropin-releasing hormone antagonist administration combined with high-dose recombinant follicle-stimulating hormone and clomiphene citrate for poor responders and women over 35 years. Fertil Steril. 2004;81(6):1572-7. Doi: 10.1016/j.fertnstert. 2004. 01.022 .

15. Olivennes F, Cunha-Filho JS, Fanchin R, Bouchard P, Frydman R. The use of GnRH antagonists in ovarian stimulation. Hum Reprod Update. 2002 May-Jun;8(3):279-90. Doi: 10.1093/humupd/8.3.279. PMID: 12078838.

16. Salustri A, Camaioni A and D'Alessandris C. Endocrine and paracrine regulation of cumulus expansion. Zygote. 1996;4(4):313-5. Doi: 10.1017/s0967199400003312. 
17. Ploutarchou P, Melo P, Day AJ, Milner CM, Williams SA. Molecular analysis of the cumulus matrix: insights from mice with O-glycan-deficient oocytes. Reproduction. 2015;149(5):533-43. Doi: 10.1530/REP-14-0503.

18. Olivennes F, Cunha-Filho JS, Fanchin R, Bouchard P, Frydman R. The use of GnRH antagonists in ovarian stimulation. Hum Reprod Update. 2002 May-Jun;8(3):279-90. Doi: 10.1093/humupd/8.3.279. PMID: 12078838.

19. Ievoli E, Lindstedt R, Inforzato A, Camaioni A, Palone F, Day AJ, et al. Implication of the oligomeric state of the Nterminal PTX3 domain in cumulus matrix assembly. Matrix Biology. 2011;30(5-6):330-7. Doi: 10.1016/j.matbio.2011.05.002.

20. Bedfort JM, Mock OB, Phlips DM. Unusual ampullary sperm cyrpts, and behaivor and role of cumulus oophorus, in oviduct of the leats shrew. Cryptosis Parva. Biol Reprod. 1997;56(5):1255-67. Doi: 10.1095/biolreprod56.5.1255.

21. Gebhardt KM. Feil DK. Dunning KR. Lane M. Russell DL. Human cumulus cell gene expression as a biomarker of pregnancy outcome after single embryo transfer. Fertil Steril. 2011;96:47-52

22. Huang X. Hao C. Shen X. et al. RUNX2, GPX3 and PTX3 gene expression profiling in cumulus cells are reflective oocyte/embryo competence and potentially reliable predictors of embryo developmental competence in PCOS patients. Reprod Biol Endocrinol.2013;11:109 Doi.org/ 10.1186/1477-7827-11-109

23. Li X. Wang H. Sheng Y. Wang Z. MicroRNA-224 delays oocyte maturation through targeting Ptx3 in cumulus cells, Mechanisms of Development. 2017;143:20-5, Doi.org/10.1016/j.mod. 2016.12.004.

24. Zhang X, Jafari N, Barnes RB, Confino E, Milad M, Kazer RR. Studies of gene expression in human cumulus cells indicate pentraxin 3 as a possible marker for oocyte quality. Fertil Steril. 2005;83 Suppl 1:1169-79. Doi: 10.1016/j.fertnstert.2004.11.030.

25. Kordus RJ, LaVoie HA. Granulosa cell biomarkers to pre- dict pregnancy in ART: pieces to solve the puzzle. Reproduction. 2017;153(2): R69-R83. Doi: 10.1530/REP16-0500.

26. Nagyova E, Camaioni S, Mlynarcikova A, Prochazka R, Nemcova L, et al. Activation of cumulus cell SMAD2/3 and epidermal growth factor receptor pathways are involved in porcine oocyte-cumulus cell expansion and steroidogenesis. Mol Reprod Dev. 2011;78(6):391-402. Doi: $10.1002 / \mathrm{mrd} .21312$

27. Nagyova E, Kalous J, Nemcova L. Increased expression of pentraxin 3 after in vivo and in vitro stimulation with gonadotropins in porcine oocyte-cumulus complexes and granulosa cells. Domest Anim Endocrinol. 2016;56:2935. Doi: 10.1016/j.domaniend.2016.01.004.

28. Paffoni A, Ragni G, Doni A, Somigliana E, Pasqualini F, et al. Follicular fluid levels of the long pentraxin PTX3. J Soc Gynecol Investig. 2006;13(3):226-31. Doi: 10.1016/ j.jsgi.2005.12.008.

29. Loutradis D, Drakakis P, Kallianidis K, Milingos S, Dendrinos S, Michalas S. Oocyte morphology correlates with embryo quality and pregnancy rate after intracytoplasmic sperm injection. Fertil Steril. 1999;72(2):240-4. Doi: 10.1016/s0015-0282(99)00233-2.

30. Seli E, Bruce C, Botros L, Henson M, Roos P, Judge K et al. Receiver operating characteristic (ROC) analysis of day 5 morphology grading and metabolomic Viability Score on predicting implantation outcome. J Assist Reprod Genet. 2011;28(2):137-44. Doi: 10.1007/s10815010-9501-9.

31. Varani S, Elvin JA, Yan C, DeMayo J, DeMayo FJ, Horton HF, et al. Knockout of pentraxin 3, a downstream target of growth differentiation factor-9, causes female subfertility. Mol Endocrinol. 2002;16(6):1154-67. Doi: 10.1210/mend.16.6.0859.

32. Camaioni A, Klinger FG, Campagnolo L, Salustri A. The influence of pentraxin 3 on the ovarian function and its impact on fertility. Front Immunol. 2018;9:2808. Doi: 10.3389/fimmu.2018.02808. 